\title{
Андрей Ходорчук
}

Евангельский Теологический Университет_

\section{Педагогический аспект формирования критического мышления у студентов философии и богословия}

Данная статья имеет перед собою цель сформировать и раскрыть педагогические инструменты для развития критического мышления у студентов, изучающих философию и богословие. Для более широкого анализа предмета, рассматриваются альтернативные варианты, существующие в педагогике и философии. Критическое мышление рассматривается с педагогической точки зрения, но сконцентрировано и направлено более для обучения студентов, изучающих философские и богословские дисциплины.

В статье сделан акцент не только на умение получать информацию, но и критически оценивать ее, осмысливать и практически применять. Студенты могут получить инструментарий как рассматривать информацию с различных точек зрения, делать выводы относительно ее ценности и точности. Для этих целей в первой части работы проанализирована педагогическая модель американского педагога Р. Энниса, в которой он предлагает три фазы развития критического мышления для обучения, а именно: заботиться о том, чтобы взгляды, решения, были чётко обоснованы, быть способным чётко представить, как свою позицию, так и позицию других, уважать мнение и достоинство собеседника. В статье также представлена и рассмотрена и позиция известного американского психолога Дайаны Халперн, развивающей в США программу критичного мышления, которая также представляет свою модель, в которой Халперн считает, что выработка установки на критическое мышление не менее важна, чем развитие самых навыков мышления. Психолог описывает следующие качества критически мыслящего человека: Готовность к планированию; Гибкость; Настойчивость; Готовность исправлять ошибки; Осознание; Поиск компромиссных решений.

В работе также представлена технология под названием «Развитие критического мышления», разработана Международной ассоциацией чтения университета Северной Айовы и колледжей Хобарда и Уильяма Смита. Авторы программы - Чарльз Темпл, Джинни Стил, Курт Мередит. Особенность данной технологии в предложении важных «трех фаз вызова» для развития критического мышления у студентов философии и богословия. Под конец данной работы, предложено рассмотреть, чем не является критическое мышление. Для этого автор обращается к исследованиям по критическому мышлению доктора Дэвида Клустера.

Ключевые слова: педагогика, философия, осмысление, критическое мылиение, богословие, психология, обучение

\section{Andrii Khodorchuk}

Evangelical Theological University

\section{Pedagogical aspect of the formation of critical thinking in students of philosophy and theology}

The purpose of the article is to reveal and form pedagogical tools for development of critical thinking of students who study philosophy and theology. Alternative variants existing in pedagogy and philosophy are considered for wider analysis of the subject. Critical thinking is considered from the pedagogical point of view, but is focused and addressed more for teaching students who study philosophical and theological subjects. The article emphasizes not just the ability to receive information but also to critically evaluate it, comprehend and practically apply. Students can get tools to consider information from various points of view, and to draw conclusions about its value and accuracy. For these purposes, the first part of the article contains the analysis of the pedagogical model of the American teacher Robert H. Ennis, in which he suggests some phases of development of critical thinking for learning, namely to care that views and decisions are justified, to be able to introduce your own position and the position of others, and to respect opinions and dignity. The article also introduces and considers a position of the prominent American psychologist Diane Halpern, who is developing a critical thinking program in the USA and is introducing her own model in which she thinks that developing a habit to think critically is no less important than developing a habit to think. The psychologist describes the following qualities of a critically thinking person: readiness for planning, flexibility, persistence, readiness for correcting mistakes, awareness, and search for compromise solutions.

This work also presents a technology called "Critical Thinking Development" designed by the International Reading Association of the University of Northern Iowa and the colleges of Hobard and William Smith. The authors 
of the program are Charles Temple, Ginny Steele, and Kurt Meredith. The peculiarity of this technology is in the presented idea of "three phases of challenge" for critical thinking development for students of philosophy and theology. The last part of this article points out what is not considered to be critical thinking. The author refers to the works on critical thinking by Dr. David J. Klooster.

Keywords: Christianity, method, person, personalism, phenomenology, philosophical anthropology, religion, Thomism

\section{Андрій Ходорчук}

Євангельський Теологічний Університет

\section{Педагогічний аспект формування критичного мислення у студентів філософії та богослов'я}

Ця стаття має перед собою мету сформувати і розкрити педагогічні інструменти для розвитку критичного мислення у студентів, що вивчають філософію і богослов'я. Для ширшого аналізу предмету, розглядаються альтернативні варіанти, існуючі в педагогіці і філософії. Критичне мислення розглядається 3 педагогічної точки зору, але сконцентроване і спрямоване більше для навчання студентів, що вивчають філософські і богословські дисципліни.

У статті зроблений акцент не лише на уміння отримувати інформацію, але і критично оцінювати iii, осмислювати і практично застосовувати. Студенти можуть отримати інструментарій як розглядати інформацію з різних точок зору, робити висновки відносно пї цінності і точності. Для цих цілей, в першій частині роботи проаналізована педагогічна модель американського педагога Р. Енніса, в якій він пропонує три фази розвитку критичного мислення для навчання, а саме: піклуватися про те, щоб погляди, рішення, були чітко обгрунтовані, бути здатним чітко представити, як свою позицію, так і позицію інших, поважати думку і гідність. У статті також представлена і розглянута і позиція відомого американського психолога Дайани Халперн, яка розвиває в США програму критичного мислення, і представляє свою модель, де вона вважає, що вироблення установки на критичне мислення не менш важливе, чим розвиток самих навичок мислення. Психолог описує наступні якості критично мислячої людини: готовність до планування; гнучкість; наполегливість; готовність виправляти помилки; усвідомлення; пошук компромісних рішень.

У роботі також представлена технологія під назвою «Розвиток критичного мислення», розроблена Міжнародною асоціацією читання університету Північної Айови і коледжів Хобарда і Вільяма Сміта. Автори програми - Чарльз Темпл, Джинні Стіл, Курт Мередіт. Особливість цієї технології в запропонованій ідеї «трьох фаз виклику» для розвитку критичного мислення у студентів філософії і богослов'я. Під кінець цієї роботи, запропоновано розглянути, чим не являється критичне мислення. Для цього автор звертається до досліджень по критичному мисленню доктора Девіда Клустера.

Ключові слова: педагогіка, філософія, осмислення, критичне мислення, богослов'я, психологія, навчання

\section{Актуальность темы.}

$\mathrm{M}$ ыслить критически, люди довольно часто просто боятся, так как привыкли жить лишь мнением и советами окружающих. Это вошло в привычку, а затем в характер. Критическое мышление способно открыть многим глаза на истинную суть вещей, в том числе и духовную. Многие лидеры разных социальных и религиозных движений пытаются всячески скрыть истинную сущность их организаций от последователей с целью махинаций и ложного обучения. Критическое осмысление реальности помогает более глубоко и шире понять саму реальность. Мышление с приставкой «критическое» способствует правильной постановке вопросов и, конечно же, их решению.

\section{Постановка проблемы.}

Как показывает практика, довольно часто, оканчивая вузы по специальности философия или богословие, студенты не способны сами критически оценивать входящую информацию, классифицировать ее и уметь аргументировано и критически осмысливать. Как результат такие выпускники учебных заведений не в состоянии моделировать ситуации, развиваться самостоятельно и обучать этому других.

Анализ последних исследований и публикаций. Рассуждения автора в первую очередь основаны на работах отечественных и зарубежных авторов данной тематики, 
a именно: Энниса Р, Дайани Халперн, Маклакова А, Сорина Г., Дэвида Клустера, Дж Дьюи, Джона Бина, Петричук И., Жакулина И., Стила Д., Московская Н. и др.

Постановка цели. Педагогически научить студентов богословия и философии, правильно формировать, а также уметь постоянно использовать критическое мышление в своей повседневной жизни и особенно - в преподавании.

\section{Изложение основного материала} исследования.

В мире существует множество разработанных моделей и форм мышления, обучения и общения, в том числе и по отношению к нашей теме о критическом мышлении. «Идеальное критическое мышление человека обычно связано с любознательностью, хорошей осведомленностью, причиной доверия, непредубежденностью, гибкостью, справедливостью в оценке, честностью в столкновении с личными предубеждениями, благоразумием в суждениях, желанием пересматривать, прояснять проблемы и сложные вопросы, тщательностью в поиске нужной информации, разумностью в выборе критериев, постоянностью в поиске результатов, которые являются столь же точными, как использованные первоисточники» (Ruminski, Hanks, 1995, p. 23). Мы рассмотрим две важные модели критического мышления.

Одна из самых популярных концепций критического мышления принадлежит американскому педагогу Р. Эннису, который одним из первых разработал систему установок или готовностей (dispositions) к критическому мышлению, или, другими словами, внутренних мотиваций, влияющих на «качество» мышления. Согласно концепции Р. Энниса критически мыслящий человек должен: Во-первых: заботиться о том, чтобы его взгляды, решения, были чётко обоснованы, а для этого ему необходимо: А) Стремиться к поиску новых гипотез, альтернативных объяснений, источников, выводов; Б) Быть хорошо информированным; В) Рассматривать точки зрения, отличные от своих собственных; Г) Расширять свой кругозор, стремиться к разносторонней осведомлённости. Вовторых: быть способным чётко представить как свою позицию, так и позицию других, а именно: А) Ясно и точно понимать смысл сказанного и написанного, принимая во внимание особенности ситуации; Б) Концентрироваться на выводе или вопросе, стремиться придерживаться основной темы; В) Искать и предлагать доводы (обоснования); Г) Принимать во внимание всю ситуацию в целом; Д) Осознавать собственные убеждения. Уважать мнение и достоинство собеседника, т.е.: А) уметь слушать и слышать других; Б) избегать критических замечаний, принимая во внимание чувства собеседника, быть восприимчивым и стремиться к пониманию чужих чувств, уровня познаний и глубины суждений; В) быть внимательным к состоянию другого человека (Московская, 2010, c. 37).

Немаловажным является и позиция известного американского психолога Дайаны Халперн, развивающей в США программу критичного мышления, которая также представляет свою модель. Она считает, что существенным компонентом критического мышления является развитие установки на то, чтобы мыслить критически и готовности к этому. Критически мыслят те, кто понастоящему умеют думать, знают, зачем им это нужно, и готовы приложить все усилия, которые требуются для планомерной работы, выверенных действий, сбора информации и проявления определенного упорства, когда решение не очевидно или требует нескольких шагов. Выработка установки на критическое мышление не менее важна, чем развитие навыков мышления. Д. Халперн описывает следующие качества критически мыслящего человека: а) Готовность к планированию; Гибкость; Настойчивость; Готовность исправлять ошибки; Осознание; Поиск компромиссных решений; (Халперн, 2020 , с. $17-18)$.

Глядя на концепцию Халперн, можно прийти к выводу, что здесь присутствует невидимый призыв, не боятся изменений или отказа от прежних понятий и утверждений, если это будет необходимо. Критическимыслящий человек не боится принять вызов, рискнуть, но не глупым риском, а тщательно обдуманным и пережитым своим сознанием. Во-первых, составляется план действий в котором обдумываются детали, 
даже самые мелкие, затем идет процесс поиска других решений проблемы или вопроса со стороны окружающих людей. Немаловажным является и настойчивость или стремление найти истину или решить проблему. Конечно же будут ошибки, но они не должны останавливать развитие, ранение - это не помеха, по гордость и слава для любого солдата впоследствии. Осознание или рефлексия, в этом списке является важнейшим элементом.

Рефлексия как необходимое условие и неотъемлемая часть критического мышления нашла отражение в определении Р. Пола, директора Центра критического мышления и моральной критики в США: «Критическое мышление - это размышление о мышлении, когда вы размышляете с целью улучшить свое мышление... При этом два момента имеют определяющее значение: критическое мышление - это влекущее за собой самоусовершенствование; и это усовершенствование приходит с навыками использования стандартов корректной оценки мыслительного процесса» (Paul, 1990, с. 91). Пауль пишет, что критическое мышление - это своего рода «мышление о знании», которое позволяет «использовать ранее приобретенные знания, чтобы создавать новые» (Paul, 1990, с. 101), при этом знание используется в пространном или широком смысле этого слова. М. Мейсон считает, что это может быть: «...определённый объём знаний, будь то знание основных понятий, относящихся к критическому мышлению, или знание той или иной научной дисциплины, к которой критическое мышление может быть в последствии применено» (Mason, 2008, с. 33)

Но есть и интересные расхождения касательно последнего момента. Так, например, Р. Эннис полагает, что критическое мышление, являясь междисциплинарной и над предметной категорией, носит дедуктивный характер: «учащийся овладевает интеллектуальными умениями критического мышления вне конкретной научной дисциплины и может применять их в различных областях знаний». В то время как Дж. Мак Пэк подчеркивает индуктивный характер критического мышления, полагая, что оно неотделимо от конкретной научной области и что необходимым условием критического рассмотрения проблем той или иной научной дисциплины является глубокое знание этой самой дисциплины. «Мы не можем критически рассматривать проблемы ядерной физики, не зная самой ядерной физики», - пишет автор (Московская, 2010, c. 45)

Дальше стоит рассмотреть три основные фазы, которыепомогают развить критическое мышление у студента благодаря интенсивной помощи преподавателя. Технологию, которую мы приводим здесь известна как «Развитие критического мышления». Эта технология разработана Международной ассоциацией чтения университета Северной Айовы и колледжей Хобарда и Уильяма Смита. Авторы программы - Чарльз Темпл, Джинни Стил, Курт Мередит (Жакулина, 2009).

Фаза вызова (evocation). Часто отсутствие результативности обучения объясняется тем обстоятельством, что преподаватель конструирует процесс обучения, исходя из поставленных им целей, подразумевая, что эти цели изначально приняты учащимися как собственные. Действительно, постановка целей преподавателем происходит заранее, что и позволяет ему более четко проектировать этапы учебного процесса, определять критерии его результативности и способы диагностики. В то же время многие известные ученые-дидакты, которые развивают в своих исследованиях идеи конструктивистского подхода в обучении (Дж. Дьюи, Б. Блум и другие), считают, что необходимо дать возможность учащемуся самому поставить цели обучения, создающие необходимый внутренний мотив к процессу учения. Только после этого преподаватель может выбрать эффективные методы для достижения этих целей. Вспомним, что мы усваиваем лучше всего? Обычно это информация по той теме, о которой мы уже что-то знаем. Когда нам проще принять решение? Когда то, что мы делаем, согласуется с имеющимся опытом, пусть и опосредованно (Жакулина, 2009).

Исаев и Сластенин называют еще этот подход «технологией конструирования педагогического процесса», утверждая, что такая технология не может быть сведена к обдумыванию лишь действий педагога, содержания и возможностей использования педагогических средств. Он должна 
осуществляться с ориентацией на учащихся, группу школьников и каждого в отдельности. Другими словами, такая технология требует предположительного конструирования действий учащихся (Сластенин, \& Исаев, 1997 , с. 287)

Второй задачей, согласно Стилу и Меридиту, которая решается на фазе вызова, является задача активизации познавательной деятельности учеников. Нередко мы видим, что некоторые студенты на уроке не прикладывают значительных интеллектуальных усилий, предпочитая дождаться момента, когда другие выполнят предложенную задачу. Поэтому важно, чтобы на фазе вызова каждый смогпринять участиев работе, ставящей своей целью актуализацию собственного опыта. Немаловажным аспектом при реализации фазы вызова является систематизация всей информации, которая появилась в результате свободных высказываний учащихся. С другой стороны, упорядочивание высказанных мнений позволит увидеть противоречия, нестыковку, не проясненные моменты, которые и определят направления дальнейшего поиска в ходе изучения новой информации. Причем для каждого из учащихся эти направления могут быть индивидуальными. В процессе реализации фазы вызова: 1) Учащиеся могут высказывать свою точку зрения по поводу изучаемой темы, делая это свободно, без боязни ошибиться и быть исправленным преподавателем; 2). Важно, чтобы высказывания фиксировались, любое из них будет важным для дальнейшей работы. При этом на данном этапе нет «правильных» или «неправильных» высказываний; 3).Целесообразносочетаниеиндивидуальной и групповой работы. Индивидуальная работа позволит каждому ученику актуализировать свои знания и опыт. Обмен мнениями может способствовать и выработке новых идей, которые часто являются неожиданными и продуктивными (Стил, Мередит, Темпл, Уолтер, с. 318-321).

Роль преподавателя на этом этапе работы состоит в том, чтобы стимулировать учащихся к вспоминанию того, что они уже знают по изучаемой теме, способствовать бесконфликтному обмену мнениями в группах, фиксации и систематизации информации, полученной от школьников.
Иногда может возникнуть ситуация, когда заявленная тема незнакома учащимся, когда у них нет достаточных знаний и опыта для выработки суждений, и умозаключений. В этом случае можно попросить их высказать предположения или прогноз о возможном предмете и объекте изучения. В случае успешной реализации фазы вызова у учебной аудитории возникает мощный стимул для работы на следующем этапе - этапе получения новой информации (Петричук, 2011, c. 3).

Фаза осмысления содержания (realization of mening). Втора фаза является очень важной, некоторые педагоги считают, что фаза осмысления для студентов самая сложная, но актуальная. Этот этап можно по-другому назвать смысловой стадией. На большинстве уроков в школе, где изучается новый материал, эта фаза занимает наибольшее время. Чаще всего знакомство c новой информацией происходит в процессе еe изложения преподавателем, гораздо реже - в процессе чтения или просмотра материалов на видео или через компьютерные обучающие программы. Вместе с тем в процессе реализации смысловой стадии школьники вступают в контакт с новой информацией. Быстрый темп изложения нового материала в режиме слушания и письма практически исключает возможность его осмысления.

Одним из условий развития критического мышления является отслеживание своего понимания при работе с изучаемым материалом. Именно данная задача является основной в процессе обучения на фазе осмысления содержания. Важным моментом является получение новой информации по теме. Если помнить о том, что на фазе вызова учащиеся определили направления своего познания, то учитель в процессе объяснения имеет возможность расставить акценты в соответствии с ожиданиями и заданными вопросами. Организация работы на данном этапе может быть различной. Это может быть рассказ, лекция, индивидуальное, парное или групповое чтение, или просмотр видеоматериала. В любом случае это будет индивидуальное принятие и отслеживание информации. Авторы педагогической технологии развития критического мышления отмечают, что в процессе 
реализации смысловой стадии главная задача состоит в том, чтобы поддерживать активность учащихся, их интерес и инерцию движения, созданную во время фазы вызова. В этом смысле значение имеет качество отобранного материала (Стил, Мередит, Темпл, \& Уолтер, с. 332).

Иногда, далее в случае удачно реализованной фазы вызова, в процессе работы на фазе реализации интерес и активность учащихся ослабевают. Этому может быть несколько объяснений. Во-первых, тот текст или сообщение, которые содержат информацию по новой теме, могут не отвечать ожиданиям школьников. Они могут быть или слишком сложными, или не содержать ответы на поставленные на первой фазе вопросы. В этом плане несколько легче организовывать изучение новой темы в режиме слушания. Однако, учитывая психологические особенности восприятия лекции, необходимо использовать специальные приемы активизации внимания и стимулирования критического осмысления. Работа в режиме чтения более сложна для организации. Но, как отмечают авторы педагогической технологии развития критического мышления, чтение в гораздо большей степени стимулирует процесс критического осмысления, так как это сам по себе процесс индивидуальный, не регламентированный по скорости восприятия новой информации. Таким образом, в процессе чтения школьники имеют возможность перечитать непонятное, отметить наиболее важные фрагменты, обратиться к дополнительным источникам. Во-вторых, учитель не всегда использует возможные приемы стимулирования внимания и активно, хотя данные приемы достаточно хорошо известны. Это и проблемные вопросы по ходу объяснения рассказа, графическое представление материала, интересные факты и комментарии. Кроме того, существуют приемы для вдумчивого чтения.

Нельзя не обратить внимание на еще одно обстоятельство. Так же, как и на первой стадии работы в режиме технологии развития критического мышления, на смысловой стадии учащиеся самостоятельно продолжают активно конструировать цели своего учения. Постановка целей в процессе знакомства с новой информацией осуществляется при ее наложении на уже имеющиеся знания. Школьники могут найти ответы на ранее заданные вопросы, решить возникшие на начальном этапе работы затруднения. Но далеко не все вопросы и затруднения могут быть разрешены. В этом случае важно, чтобы учитель стимулировал учащихся к постановке новых вопросов, поиск ответов через контекст той информации, с которой учащиеся работают. На фазе осмысления содержания учащиеся: А) Осуществляют контакт с новой информацией; Б) Пытаются сопоставить эту информацию с уже имеющимися знаниями и опытом; В) Акцентируют свое внимание на поиске ответов на возникшие ранее вопросы и затруднения; Г) Обращают внимание на неясности, пытаясь поставить новые вопросы; Д) Стремятся отследить сам процесс знакомства с новой информацией, обратить внимание на то, что именно привлекает их внимание, какие аспекты менее интересны и почему; Е) Готовятся к анализу и обсуждению услышанного или прочитанного (Стил, Мередит, Темпл, Уолтер, с. 335-337).

Преподаватель на данном этапе: А) Может быть непосредственным источником новой информации. В этом случае его задача состоит в ее ясном и привлекательном изложении; Б) Если школьники работают с текстом, учитель отслеживает степень активности работы, внимательности при чтении; В) Для организации работы с текстом учитель предлагает различные приемы для вдумчивого чтения и размышления о прочитанном (Стил, Мередит, Темпл, Уолтер, с. 339).

Фаза рефлексии (reflection). Роберт Бустром в книге «Развитие творческого и критического мышления» отмечает: «Рефлексия - особый вид мышления... Рефлексивное мышление - значит фокусирование вашего внимания. Оно означает тщательное взвешивание, оценку и выбор». В процессе рефлексии та информация, которая была новой, становится присвоенной, превращается в собственное знание. Анализируя функции двух первых фаз технологии развития критического мышления, можно сделать вывод о том, 
что, по сути, рефлексивный анализ и оценка пронизывают все этапы работы. Однако рефлексия на фазах вызова и реализации имеет другие формы и функции. На третьей же фазе рефлексия процесса становится основной целью деятельности школьников и учителя (Бустром, 2000, с. 122)

Часто на детальную рефлексию практически не остается времени. Мы отмечали, что большое внимание на уроках уделяется, прежде всего, изложению нового материала. Студенты не очень привыкли к тому, что после этого этапа им могут быть заданы вопросы типа: «Какая информация привлекла Ваше внимание?», «Что Вы делали для того, чтобы выделить основную мысль прочитанного текста?» и тому подобные. Еще большую растерянность может вызвать предложение учителя поделиться в парах или в группе мнениями о возникших по ходу урока вопросах. Все это свидетельствует о том, что рефлексия в обучении не может проводиться спонтанно. Она требует систематичности на всех этапах работы, а также регулярности и методической последовательности (Бустром, 2000, с. 139-140)

Рефлексивный анализ направлен на прояснение смысла нового материала, построение дальнейшего маршрута обучения (это понятно, это непонятно, об этом необходимо узнать еще, по этому поводу лучше было бы задать вопрос и так далее). Но этот анализ малополезен, если он не обращен в словесную или письменную форму. Именно в процессе вербализации тот хаос мыслей, который был в сознании в процессе самостоятельного осмысления, структурируется, превращаясь в новое знание. Возникшие вопросы или сомнения могут быть разрешены. Кроме того, в процессе обмена мнениями по поводу прочитанного или услышанного учащиеся имеют возможность осознать, что один и тот же текст может вызывать различные оценки, которые отличаются по форме и по содержанию. Некоторые из суждений других школьников могут оказаться вполне приемлемыми для принятия как своих собственных. Другие суждения вызывают потребность в дискуссии. В любом случае этап рефлексии активно способствует развитию навыков критического мышления (Стил, Мередит, Темпл, \& Уолтер, с. 109).
Итак, каковы механизмы реализации фазы рефлексии при работе в режиме технологии развития критического мышления? Не вызывает никаких сомнений важность отслеживания развития знаний учащихся. Механизм этого развития можно представить следующим образом: Актуализация имеющихся знаний, выявление затруднений и пробелов в знаниях, формулировка вопросов.

Итог - постановка целей учебной деятельности. Знакомство с новой информацией, еe соотнесение с имеющимися знаниями, поиск ответов на поставленные ранее вопросы, выявление затруднений и противоречий, корректировка целей. Суммирование и систематизация новой информации, ее оценка, ответы на поставленные ранее вопросы, формулировка вопросов, постановка новых целей учебной деятельности (Стил, Мередит, Темпл, \& Уолтер, с. 216).

Педагог Ирина Петричук замечает: «Важно, чтобы в процессе рефлексии учащиеся самостоятельно могли оценить свой путь от представления к пониманию. Еще более важно, чтобы этот процесс осуществлялся без принуждения со стороны преподавателя. Каким образом учитель может стимулировать рефлексию? Б. Блум считал, что таким действенным механизмом могут быть вопросы, заданные преподавателем, а также побуждение к постановке вопросов учащимися. Еще одним стимулом активизации рефлексии являются субъективные суждения самого учителя по поводу происходящего на уроке. Это предполагает не только оценочные суждения о действиях учащихся, но и оценку своих ощущений, выражение собственных сомнений. Искренность и позиция партнерства позволяют сделать атмосферу обсуждения более открытой, а результаты более плодотворными» (Петричук, 2011)

В процессе индивидуальной работы (различные виды письма: эссе, ключевые слова, графическая организация материала и так далее) ученики, с одной стороны, производят отбор информации, наиболее значимой для понимания сути изучаемой темы, а также наиболее значимой для реализации поставленных ранее индивидуально целей. С другой стороны, они выражают новые идеи и информацию 
собственными словами, самостоятельно выстраивают причинно-следственные связи. Учащиеся помнят лучше всего то, что они поняли в собственном контексте, выражая это своими собственными словами. Такое понимание носит долгосрочный характер. Когда учащийся переформулирует понимание с использованием собственного словаря, то создается личный осмысленный контекст. Наряду с письменными формами не менее важной является устная рефлексия. Дж. Стил и ее коллеги - авторы педагогической технологии развития критического мышления посредством чтения и письма - отмечают, что живой обмен идеями между учащимися дает возможность расширить свой выразительный словарь, a также познакомиться с различными представлениями. Разрешая диалог на стадии рефлексии, учитель дает возможность увидеть и рассмотреть различные варианты мнений на один и тот же вопрос. Отслеживание этапов, механизма своей деятельности помогает учащемуся осознать методологию учебного и научного познания. Дж. Стил и ее коллеги подчеркивают, что преподавание является наилучшим тогда, когда оно является прозрачным, то есть когда учащиеся видят, как разворачивается учебный процесс (Стил, Мередит, Темпл, \& Уолтер, с. 318). Итак, если подвести итоги, то получится вот такой результат по трем фазам и их функциям в развитии технологии критического мышления: 1. Вызов: Мотивационная (побуждение к работе с новой информацией, пробуждение интереса к теме); Информационная (вызов «на поверхность» имеющихся знании по теме); Коммуникационная (бесконфликтный обмен мнениями); 2. Осмысление содержания: Информационная (получение новой информации по теме); Систематизационная (классификация полученной информации по категориям знания). 3. Рефлексия: Коммуникационная (обмен мнениями о новой информации); Информационная (приобретение нового знания); Мотивационная (побуждение к дальнейшему расширению информационного поля); Оценочная (соотнесение новой информации и имеющихся знаний, выработка собственной позиции, оценка процесса). Эти три фазы, о которых мы узнали выше существенно и практично показывают ход направления по развитию критического мышления. На фазе вызова создается мотивация, что многие преподаватели пропускают, сразу переходя к фазе осмысления или более того - рефлексивного восприятия материала. Это касается как студентов философских вузов, так и богословских.

Важно себе задать еще один вопрос: А чем же неявляется критическое мышление? Многие педагоги, часто пытаются выработать определенные фазы восприятия и действия у студентов думаю при этом, что способствуют критическому развитию мышления. Но все же, что такое критическое мышление или лучше спросить, чем оно не является? Для этого мы обратимся к исследованиям по критическому мышлению от доктора Дэвида Клустера.

Первое что Клустер не считает критическим мышлением, это запоминание. Старые образовательные модели именно на этоммногиегодыпыталисьсконцентрировать свою учебу, нагружая при этом учащихся большим объемом информации, но наше время - совершенно другое. Запоминание - важнейшая мыслительная операция, без которой невозможен учебный процесс, но от критического мышления оно кардинальным образом отличается. У компьютера память гораздо лучше, чем почти у любого из нас, однако мы понимаем, что его способность запоминать еще не является мышлением. Правда, многие школьные учителя по старинке ценят память превыше всякого мышления и проверяют на контрольных и экзаменах исключительно объем памяти учащихся, но мы, сторонники критического мышления, все же ориентируемся на более сложные виды умственной деятельности (Клустер, 2001, с. 166)

Во-вторых, даже само понимание, Клустер также не относит к критическому мышлению. Он считает, что критическим мышление становится лишь в момент переосмысления уже существующих идей своим сознанием. На уроках студентам приходится иногда как следует поработать головой, чтобы понять, что говорит учитель или что написано в учебнике. Понимание сложная мыслительная операция, особенно еслиматериалнеизлегких.Кпримеру, студент пытается понять сонет Шекспира или ломает 
голову над теоремой о точках экстремума. В голове его, безусловно, происходит сложный интеллектуальный процесс, но критическим мыслителем он пока не является. Некоторые учителя со мной не согласятся, считая, что истинное понимание всегда подразумевает критическое мышление, поскольку ученик переводит чужие идеи на доступный для себя язык и мыслительный уровень. Тем не менее, когда мы трудимся над пониманием чужой идеи, наше собственное мышление на первом этапе пассивно: мы лишь воспринимаем то, что создал до нас кто-то другой. А критическое мышление происходит, когда новые, уже понятые идеи проверяются, оцениваются, развиваются и применяются. Запоминание же фактов и понимание идей являются необходимыми предварительными условиями для критического мышления, однако сами они, даже в своей совокупности, критического мышления не составляют (Клустер, 2001, с. 170)

В-третьих, критическое мышление - это не творческое мышление по мнению Клустера. Он считает, что мозг спортсмена, художника, музыканта тоже проделывает сложнейшую работу, однако самиони-если, конечно, речьне идет о новичках - этого даже не замечают. Как правило, такого рода мыслительные процессы остаются неосознанными. Представим себе профессионального спортсмена, например, звезду чешского хоккея Яромира Ягра (выступающего всегда под номером 68, в память о Пражских событиях 1968 года). И предположим, что, прежде чем ударить по воротам, он размышляет примерно так: «Правильно ли выбран момент? Нет ли тут какого-нибудь альтернативного решения? Как поступили бы на моем месте другие великие игроки? Пробил бы сейчас Уэйн Грецки или дождался более удобного момента? Или вовсе передал шайбу другому игроку?» Совершенно очевидно, что при таком «сознательном» подходе Ягр вообще не забил бы ни одного гола. И если его решение носить футболку с номером 68 является, несомненно, примером критического мышления, то его же игровое решение таковым быть никак не может. Точно так же художники и музыканты, опираясь в своей работе на сложные мыслительные операции, не осознают их полностью. Их интуитивное мышление, при всей его ценности, также не может быть названо критическим (Клустер, 2001, с. 179)

А теперь наконец стоит поговорить о педагогических методах формирования критического мышления у студентов? Первое, что стоит в списке Дэвида Колистера - самостоятельность в мышлении, независимость рассуждений. Если не начать с этого - не выйдет остальное. Когда занятие строится на принципах критического мышления, каждый формулирует свои идеи, оценки и убеждения независимо от остальных. Никто не может думать критически за нас, мы делаем это исключительно для самих себя. Следовательно, мышление может быть критическим только тогда, когда оно носит индивидуальный характер. Ученики должны иметь достаточно свободы, чтобы думать собственной головой и самостоятельно решать даже самые сложные вопросы (Клустер, 2001, с. 194). Психолог же Маклаков А. Г. считает, что «мышление связано с деятельностью, так как в ее процессе сначала решается ряд задач, а потом умственный проект осуществляется на практике» (Маклаков, 2013, с. 187). Колистер наводит пример из своей учебной практики, когда ученики знали все о писателе, вплоть до деталей, но не читали никогда его сами, поэтому они не думали критически, а значит, не умели сформулировать личные идеи.

Во-вторых, информация является отправным, а отнюдь не конечным пунктом критического мышления. Знание создает мотивировку, без которой человек не может мыслить критически. Как иногда говорят, «трудно думать с пустой головой». Чтобы породить сложную мысль, нужно переработать гору «сырья» - фактов, идей, текстов, теорий, данных, концепций вопросы (Клустер, 2001, с. 211). Но знание не есть цель, а лишь поезд, который доставит к ней. Критическое мышление вырабатывает более лучшие пути к практическому решению проблемы. «Критическому мышлению в целом свойственна практическая ориентация. В силу этого оно может быть проинтерпретировано как форма практической логики» (Сорина, 2003, с. 21). Мыслить можно постоянно и можно постоянно это развивать. В своей познавательной 
деятельности студенты и учителя, писатели и ученые подвергают каждый новый факт критическому обдумыванию. Именно благодаря критическому мышлению традиционный процесс познания обретает индивидуальность и становится осмысленным, непрерывным и продуктивным.

Следующим важной составляющей, есть умение вырабатывать в себе вопросы. Эти вопросы должны быть не чужие, но взяты «изнутри». Человеческие существа любопытны по своей природе. Мы замечаем что-то новое - и хотим узнать, что это такое. Мы видим некую достопримечательность и нам уже хочется проникнуть внутрь. «Во всем животном мире, - отмечает химик и философ Микаел Поланый, - начиная от таких простейших форм, как черви и, возможно, даже амебы, мы наблюдаем вечное настороженное копошение, чисто исследовательскую активность, не связанную с прямым удовлетворением потребностей: стремление всякого живого существа к интеллектуальному контролю над своим окружением» (Meyers, 1986, c. 55). Любопытство, таким образом, есть неотъемлемое свойство всего живого. Мы с вами больше привыкли наблюдать это свойство у малышей, чем у старшеклассников и студентов - увы, зачастую таково воздействие школьного образования на детские умы (Meyers, 1986, с. 68). Поэтому очень важно, чтобы воспринимающий информацию, умел сам искать в себе вопросы, которые напрашиваются в этой ситуации. Проявление скрытого и обьяснение, вот что важно в критическом мышлении. «Следовательно, - заключает Джон Бин, - сложность обучения критическому мышлению состоит отчасти в том, чтобы помочь ученикам разглядеть бесконечное многообразие окружающих нас проблем» (Bean, 1996, с. 213). Некоторые учителя боятся открыть глаза не реальную сущность вопроса, но критическое мышление именно сосредоточено на практической реальности какова бы она не была. Бразильский педагог Пауло Фрейре придерживается мнения, что надо заменить традиционное «накопительное» образование - при котором головы учеников служат своеобразными «счетами», на которые учителя кладут знания, - на образование «проблемнопостановочное», когда ученики занимаются реальными, взятыми из жизни проблемами. Учение, считает он, пойдет гораздо успешнее, если ученики будут формулировать проблемы - в том числе экономические, общественные и политические - на основе собственного жизненного опыта и затем решать их, используя при этом все возможности, которые предоставляет ему школа. Особенно много внимания Фрейре уделяет вопросам подавления личности. Он уверен, что правильно организованное образование способно освободить учеников от этого подавления, поэтому его образовательная концепция называется «освободительной педагогикой» (Фрейре, 1998, с. 109). Интересную мысль предлагает американский педагог Джон Дьюи. Он считает, что важнейшим элементом критического мышление есть тот факт что студенты сами занимаются конкретной проблемой. «Только сражаясь с конкретной проблемой, отыскивая собственный выход из сложной ситуации, (ученик) действительно думает» пишет он (Дьюи, 2000, с. 215).

Известный философ Б. Спиноза както выразил один из важных принципов современного критического мышления, а именно - убедительная аргументация. Он писал: «Незнание - не довод. Невежество — не аргумент» (Спиноза, 1957, с. 511)

Критическое мышление ищет и предлагает на обозрение аргументацию. Человек, который мыслит критически, находит собственное решение проблемы и подкрепляет это решение разумными, обоснованными доводами. Он также сознает, что возможны иные решения той же проблемы, и старается доказать, что выбранное им решение логичнее и рациональнее прочих. Всякая аргументация содержит в себе три основных элемента. Центром аргументации, главным ее содержанием является утверждение (называемое также тезисом, основной идеей или положением). Утверждение поддерживается рядом доводов. Каждый из доводов, в свою очередь, подкрепляется доказательствами. В качестве доказательств могут использоваться статистические данные, выдержки из текста, личный опыт и вообще все, что говорит в пользу данной 
аргументации и может быть признано другими участниками обсуждения. Под всеми названными элементами аргументации утверждением, доводами и доказательствами - лежит элемент четвертый: основание. Основание - это некая общая посылка, точка отсчета, которая является общей для оратора или писателя и его аудитории, и которая дает обоснование всей аргументации. Аргументация выигрывает, если учитывает существование возможных контраргументов, которые либо оспариваются, либо признаются допустимыми. Признание иных точек знания только усиливает аргументацию (Дьюи, 2000, с. 106-107).

Последний фактор согласно Колистеру, это социальный фактор. Всякая идея, которую мы представляем, мы представляем ее кому-то, а это значит, что она должна пройти «общий обзор». Всякая мысль проверяется и оттачивается, когда ею делятся с другими, - или, как пишет философ Ханна Арендт, «совершенство может быть достигнуто только в чьем-то присутствии» (Kaplan, Kessler, \& Arendt, 1990, с. 98). Когда мы спорим, читаем, обсуждаем, возражаем и обмениваемся мнениями с другими людьми, мы уточняем и углубляем свою собственную позицию. Поэтому педагоги, работающие в русле критического мышления, всегда стараются использовать на своих занятиях всевозможные виды парной и групповой работы, включая проведение дебатов и дискуссий, а также различные виды публикаций письменных работ учащихся. Поэтому учителя, работающие в русле критического мышления, уделяют большое внимание выработке качеств, необходимых для продуктивного обмена мнениями: терпимости, умению слушать других, ответственности за собственную точку зрения (Клустер, 2001, с. 106)

\section{Заключение.}

Мы рассмотрели некоторые модели относительно развития критического мышления у студентов богословия и философии. Мышлению, как и всему другому - учатся. Оно развивается, оно усовершенствуется, и педагогика существенно в этом всем помогает. Итак, как мы можем подытожить - критическое мышление направленно не на себя, но на развитие общества благодаря развитию личному. Социальный фактор очень важный, поскольку играет, несомненно, одну из главных целей в нашем мышлении, помогая как нам, так и обществу. Человеку иногда кажется, что он все понимает сам, но вступая в определенные диалоги или даже дебаты с другими, он может пересмотреть или же более укрепить свою позицию.

Критически мыслить многих людей пугает, потому что существует давний стереотип относительного того, что всякая критика есть камнем в чужой огород. Проще говоря - мыслить критически сегодня для отдельных людей - значит осуждать все и вся. Это типичное явление от незнания. Цель же нашей работы - было развеять такой стиль или формат мышления, придав критическому мышлению важный фактор, который способствует более глубокому изучению и познанию в теоретической и практической жизни. Студенты философии и богословия должны научиться педагогическим приемам для лучшего осмысления и рефлексирования материалов и разных источников информации.

Современный католический богослов Ганг Кюнг писал: «Современный мир уже нельзя представить себе без развития критического мышления, науки и историкокритического метода исследования, а также без просветительского акцента на человеческой свободе и независимости. Богословие должно одним из первых признать этот факт. Но такие отрицательные, даже ненаучные элементы культуры модернизма, какдогматический рационализм и миф о неизбежности прогресса, должны уступить место более совершенным представлениям о разуме и реалистичной оценке опыта». А дальше он продолжает: «Поэтому богословы с самого начала не должны ожидать, что между евангелием, даже в лучшей историко-критической трактовке, и современным человеческим опытом будет царить ничем не нарушаемая преемственность и гармония. Иногда будут возникать конфликты и противостояния. Вот почему эта парадигма относится не к модернизму, а к постмодернизму. В случае конфликта преимущество должно быть отдано самому христианскому учению, а не диапазону современного опыта» (Гренц, \& Олсон, 2011, с. 395) 


\section{БІБЛІОГРАФІЧНІ ПОСИЛАННЯ}

Бустром Р. Развитие творческого и критического мышления. Москва : Открытое общество, 2000. 333 с. Гренц С., Олсон Р. Богословие и богословы 20-го века. Черкассы : Коллоквиум, 2011. 440 с. Дьюи Дж. Демократия и образование. Москва : Педагогика-пресс, 2000. 317 с.

Жакулина И. В. Приёмы ТРКМЧП и их применение на уроках в начальных классах. Модуль 2. 2009. № 23. URL: https://ppt-online.org/711273.

Клустер Д. Что такое критическое мышление? хМосква, 2001. № 4. С. 64.

Маклаков А. Г. Общая психология. Санкт-Петербург : Питер, 2013. 583 с.

Московская Н. Л. Критическое мышление как образовательная ценность. Ставрополь: Ставропольский государственный университет, 2010. 217 с.

Петричук И. И. Технология развития критического мышления через чтение и письмо при обучении английскому языку в контексте компетентностного подхода. Газета Интерактивное образование. Новосибирск, 2011. № 33. URL: http://io2.nios.ru/index.php?rel=33\&point=11\&art=1153.

Сластенин В. А., Исаев И. Ф., Мищенко А.И., Шиянов Е.Н. Педагогика : учеб. пос. Москва : Школа-Пресс, 1997. $411 \mathrm{c}$.

Сорина Г. В. Критическое мышление: история и современный статус. Вестник Московского университета. Философия. Москва, 2003. № 7. С. 54-55

Спиноза Б. Избранные произведения: в 2 т. Москва : Госполитиздат, 1957. Т. 1. 431 с.

Стил, Дж.Л., Мередит К.С., Темпл Ч., Уолтер С. Основы критического мышления. Москва : Открытое общество:

1997. $411 \mathrm{c}$

Фрейре Пауло. Педагогика угнетенных. Москва : Школа трудовой демократии, 1998. 216 с.

Халперн Д. Психология критического мышления. Санкт Петербург : Питер, 2000. 312 с.

Bean J. Engaging Ideas: The Professor's Guide to Integrating Writing, Critical Thinking, and Active Learning in the Classroom. Jossey-Bass Higher and Adult Education, 1996. 313 p.

$300 \mathrm{p}$.

Gisela T. Kaplan, Clive S. Kessler. Hannah Arendt: Thinking, Judging, Freedom. Crows Nest: Allen \& Unwin, 1990.

Mason M. Critical Thinking and Learning. Singapore: Blackwell Publishing, 2008. 413 p.

Paul R. Critical Thinking: What Every Person Needs to Survive in a Rapidly Changing World. CA: Center for Critical Thinking and Moral Critique, Sonoma State Univ., 1990. 345 p.

Ruminski H. J., \& Hanks W. E. Critical Thinking Lacks Definition and Uniform Evaluation Criteria. Journalism \& Mass Communication Educator, 1995. 390 p.

\section{REFERENCES}

Bean, J. (1996). Engaging Ideas: The Professor's Guide to Integrating Writing, Critical Thinking, and Active Learning in the Classroom. Jossey-Bass Higher and Adult Education.

Bustrom,R. (2000). Razvitie tvorcheskogo i kriticheskogo myshlenija [Development of creative and critical thinking]. Moskva : Otkrytoe obshhestvo [in Russian].

D'jui, Dzh. (2000). Demokratija i obrazovanie [Democracy and Education]. Moskva: Pedagogika-press [in Russian]. Frejre, Paulo. (1998). Pedagogika ugnetennyh [Pedagogy of the oppressed]. Moskva: Shkola trudovoj demokrati i [in Russian]

Gisela T. Kaplan, \& Clive S. Kessler. (1990). Hannah Arendt: Thinking, Judging, Freedom. Crows Nest: Allen \& Unwin.

Grenc, S., \& Olson, R. (2011). Bogoslovie i bogoslovy 20-go veka [Theology and theologians of the 20th century]. Cherkassy: Kollokvium [in Russian].

Halpern, D. (2000). Psihologija kriticheskogo myshlenija [Psychology of critical thinking]. Sankt Peterburg : Piter [in Russian].

Kluster, D. (2001). Chto takoe kriticheskoe myshlenie? [What is critical thinking?]. Zhurnal «Peremena», 4, 64

[in Russian].

Maklakov, A. G. (2013). Obshhaja psihologija [General psychology]. Sankt-Peterburg: Piter [in Russian].

Mason, M. (2008). Critical Thinking and Learning. Singapore: Blackwell Publishing.

Moskovskaja, N. L. (2010). Kriticheskoe myshlenie kak obrazovatel'naja cennost' [Critical thinking as an educational value]. Stavropol': Stavropol'skij osudarstvennyj universitet [in Russian].

Paul, R. (1990). Critical Thinking: What Every Person Needs to Survive in a Rapidly Changing World. CA: Center for Critical Thinking and Moral Critique, Sonoma State Univ.

Petrichuk, I. I. (2011). Tehnologija razvitija kriticheskogo myshlenija cherez chtenie i pis'mo pri obuchenii anglijskomu jazyku v kontekste kompetentnostnogo podhoda [Technology of development of critical thinking through reading and writing in teaching English in the context of a competence-based approach]. Gazeta Interaktivnoe obrazovanie, 33. Novosibirsk. Retrieved from http://io2.nios.ru/index.php?rel=33\&point=11\&art=1153 [in Russian].

Ruminski, H. J., \& Hanks, W. E. (1995). Critical Thinking Lacks Definition and Uniform Evaluation Criteria. Journalism \& Mass Communication Educator.

Slastenin, V. A., Isaev, I. F., Mishhenko, A.I., \& Shijanov, E.N. (1997). Pedagogika [Pedagogy]. Moskva: Shkola-Press [in Russian]. 
Sorina, G. V. (2003). Kriticheskoe myshlenie: istorija i sovremennyj status [Critical thinking: history and modern status]. Vestnik Moskovskogo universiteta. Filosofija-Moscow University Bulletin. Philosophy, 7, 54-55. Moskva [in Russian].

Spinoza, B. (1957). Izbrannye proizvedenija: v 2 t. [Selected works: in 2 volumes.]. (Vol. 1). Moskva: Gospolitizdat [in Russian].

Stil, Dzh.L., Meredit, K.S., Templ, Ch., \& Uolter, S. (1997). Osnovy kriticheskogo myshlenija [Fundamentals of Critical Thinking.]. Moskva : Otkrytoe obshhestvo [in Russian].

Zhakulina, I. V. (2009). Prijomy TRKMChP i ih primenenie na urokah v nachal'nyh klassah [Techniques of TRKMCHP and their application in the classroom in primary grades]. Modul' 2 - Module 2, 23. Retrieved from https://ppt-online. org/711273 [in Russian].

Khodorchuk Andrii

Applicant, https://orcid.org/0000-0001-5861-9146, kbiandrey@gmail.com

Стаття надійшла / Article arrived: 07.12.2020

Схвалено до друку / Accepted: 16.01.2021 